\title{
O SUPERIOR TRIBUNAL DE JUSTIÇA E O IMPACTO EM SUAS DECISÕES DE CONVENÇÕES E ACORDOS INTERNACIONAIS EM MATÉRIA DE PROPRIEDADE INTELECTUAL
}

\author{
EL SUPERIOR TRIBUNAL DE JUSTICIA Y EL IMPACTO EM SUS \\ DECISIONES DE CONVENCIONES Y ACUERDOS INTERNACIONALES EN \\ MATÉRIA DE PROPIEDADE INTELECTUAL
}

\author{
${ }^{1}$ Waleska Bertolini Vieira Mussalem
}

\section{RESUMO}

O presente estudo tem por objeto analisar a evolução jurisprudencial do Superior Tribunal de Justiça, nos últimos 10 (dez) anos, no que tange à aplicação de convenções e acordos internacionais aos conflitos relacionados à propriedade intelectual, sob o enfoque da internacionalização do direito. Os critérios são estudados a partir da identificação dos acordos e tratados que versem sobre os direitos de propriedade intelectual, além das legislações internas brasileiras sobre propriedade intelectual. São pesquisadas as repercussões das decisões estrangeiras perante o Superior Tribunal de Justiça, bem como analisados seus julgados em torno do tema da propriedade intelectual, sob a influência do processo de globalização. Esses critérios são utilizados para se verificar a efetiva existência do diálogo entre juízes no âmbito do Corte Superior de Justiça na matéria em referência.

Palavras-chave: Palavras-chave: propriedade intelectual, O diálogo entre juízes, O superior tribunal de justiça, Acordo trips, Convenção da união de paris, Convenção de berna

\section{RESUMEN}

El propósito del presente estudio es analisar la evolución jurisprudencial del Superior Tribunal de Justicia, en los últimos diez (10) años, con respecto a la aplicación de los convenios y acuerdos internacionales en conflictos relacionados con la propiedad intelectual, bajo la internacionalización del foco derecha. Los criterios se estudian desde la identificación de los acuerdos y tratados que se ocupan de los derechos de propiedad intelectual, más allá de la legislación interna de Brasil sobre la propiedad intelectual. Se investigan los efectos de las sentencias extranjeras ante el Superior Tribunal de Justicia y sus juzgados en el tema de la propiedad intelectual, bajo la influencia de la globalización. Estos criterios se utilizan para verificar la existencia real del "diálogo entre jueces" en la Corte Superior de Justicia en el asunto en cuestión.

Palabras clave: propiedad intelectual, El diálogo entre los jueces, El superior tribunal de justicia, El acuerdo sobre los adpic, El convenio de la unión de parís, El convenio de berna

\footnotetext{
${ }^{1}$ Mestre em Direito pelo Centro Universitário de Brasília - UniCEUB, Brasília, Distrito Federal,Brasil. Assessora de Ministro - Superior Tribunal de Justiça. E-mail: bmussalem@ hotmail.com
} 


\section{INTRODUÇÃO}

O presente artigo pretende analisar como o Superior Tribunal de Justiça vem decidindo os conflitos relacionados à propriedade intelectual cujo regramento normativo material advenha, em alguma medida, de convenções e acordos internacionais. Nesse sentido, será enfocada, especialmente, a maneira como se processa, na prática judiciária daquela Corte Superior, a internalização das regras de caráter internacional sobre propriedade intelectual na jurisprudência brasileira, considerando-se o recorte temporal dos últimos 10 (dez) anos (entre 2005 e 2015).

As escolhas do STJ e do marco temporal refletem uma estratégia metodológica que pode ser justificada pelo fato de o STJ ter a missão constitucional de uniformizar a interpretação da lei federal no país e as normas internacionais de propriedade intelectual ingressam no ordenamento com status de lei federal, de modo que os precedentes do STJ são a última palavra no que tange à interpretação dessas normas para efeito de sua aplicação no Brasil.

Quanto ao recorte temporal escolhido, vale lembrar que, nos últimos 10 anos, com o fortalecimento do processo de globalização e da relevância que a tecnologia assumiu para o desenvolvimento econômico, as questões relativas à propriedade intelectual não apenas se tornaram mais relevantes sob o ponto de vista econômico, como ainda se tornaram cada vez mais frequentes em disputas judiciais do que em um passado mais remoto.

Juntamente com o avanço da ciência, a crescente globalização e o significativo aumento das disputas judiciais, o Superior Tribunal de Justiça, em sua busca pela uniformização das leis federais brasileiras, se depara com o fenômeno conhecido como "diálogo entre juízes", que é observado em diversos tribunais, quando do uso adequado de referências cruzadas de decisões de diferentes ordens jurídicas, para a solução de situações concretas existentes nas relações jurídicas de direito privado.

Também denominado "fertilização cruzada", o fenômeno do "diálogo entre juízes" tem sido defendido por alguns doutrinadores, como forma de reduzir as incoerências do sistema jurídico alienígena frente à crescente fragmentação do direito internacional. No direito constitucional, destaca-se Marcelo Neves, enquanto nos Direitos Humanos, a frente doutrinária é ocupada por Mireille Delmas-Marty e Laurence Bougorgue-Larsesn. No Direito de Propriedade Intelectual, entretanto, ainda não há trabalhos que explore essa temática. 
Esse diálogo entre juízes de diferentes ordenamentos, embora ainda pouco estudado em nosso meio jurídico, tem se revelado, nos sistemas que o adotam, um instrumento valioso para construção de princípios e argumentos capazes de informar uma prestação jurisdicional consentânea com a envergadura dos conflitos de direitos fundamentais hoje verificados.

Por fim, o trabalho aborda a celeuma existente quanto à resistência, ou não, do Superior Tribunal de Justiça em adotar uma postura jurisdicional voltada à realidade mundial globalizada. Nesse espectro de possibilidade é que será examinado o "diálogo entre juízes” em matéria de propriedade intelectual. Para tanto serão analisados, em especial os acórdãos relacionados à Convenção de Berna, à Convenção da União de Paris, e também ao acordo TRIPS.

\section{A GLOBALIZAÇÃo E A INTERNACIONALIZAÇÃo DO DIREITO - "DIÁLOGO ENTRE JUÍZES"}

A globalização crescente ${ }^{1}$ conduz à necessidade de adequação de regras, no sentido de fornecer instrumentos hábeis para a solução dos conflitos relativos à internacionalização das relações jurídicas. Deve-se reconhecer que a imensa variedade de legislações existentes no mundo impede a criação de regras únicas para um direito comum entre os países.

Juntamente com a globalização e a informatização que decretaram significativas mudanças no modelo de Estado atual, tanto na sua relação com os cidadãos como na relação entre os Estados nacionais, a internacionalização da justiça é um dos fenômenos mais significativos do século $\mathrm{XX}^{2}$, encontrando, porém, alguns obstáculos em nosso meio jurídico.

${ }^{1}$ A respeito da globalização, Ulrich Beck afirma que: “O choque da globalização, traço marcante da transição para a segunda modernidade, tem ao seu final um efeito politizante, pois todos os atores e organizações, em todos os domínios da sociedade, precisam lidar com os paradoxos e as exigências da globalização e com a sua dinâmica que altera todos os antigos fundamentos." (BECK, Ulrick. O que é globalização? Equívocos do Globalismo: respostas à globalização. São Paulo: Paz e Terra, 1999, p. 225).

${ }^{2}$ Sob esse aspecto, Carla Patrícia Marques ressalta que: "É preciso observar que o rompimento das fronteiras territoriais leva necessariamente à derrubada em escala das fronteiras culturais, linguísticas e sociais. Esse processo exige abertura para o diálogo em sua mais ampla possibilidade multidimensional. No entanto, como visto, os julgados no âmbito da jurisprudência brasileira nem de longe acompanham esse projeto" LOPES, Carla Patrícia F. Nogueira. Internacionalização do direito e pluralismo jurídico: limites de cooperação no diálogo 
O processo de globalização e o reconhecimento da proteção jurídica de novas tecnologias impulsionaram mudanças significativas como a criação da Organização Mundial do Comércio (OMC) para supervisionar o comércio internacional entre os diversos países. ${ }^{3}$

Essa expansão da propriedade intelectual demanda a adoção de normas similares com vistas à facilitação das relações jurídicas e comerciais em âmbito internacional. Tal processo leva à possibilidade de uma comunidade mundial de valores e à conquista de um novo paradigma jurídicopolítico que ultrapassa as barreiras internas nacionais, com o reconhecimento de uma "sociedade de Estados comprometida com o cosmopolitismo".

A adoção de normas similares facilita as relações econômicas internacionais. Assim, as decisões passam a respeitar o direito como integridade, com respostas orientadas por razões de princípio, não por razões de política, como é a exigência neoconstitucional contemporânea. ${ }^{5}$

Ressalte-se que o fenômeno do "diálogo entre juízes" é pesquisado por vários autores no campo constitucional, como Marcelo Neves. No campo dos Direitos humanos, a pesquisa é feita por Mireille Delmas Marty e Laurence Bougorgue-Larsesn. Contudo, ainda não há trabalhos sobre o tema da propriedade intelectual que explore essa temática.

Marcelo Neves identifica a figura do "transconstitucionalismo" para a solução de um caso constitucional (por exemplo, de direitos fundamentais), onde as diversas ordens jurídicas entrelaçadas buscam formas transversais. Por sua vez, a professora Meirelle Delmas Marty sustenta a construção de uma comunidade mundial de juízes preocupados em aplicar uniformemente as

entre juízes. Revista de Direito Internacional, Brasília, v. 9, n. 4, 2012, p. 229-247. Disponível em: http://www.tjdft.jus.br/institucional/imprensa/noticias/arquivos/Carla.pdf, p. 246. Acesso em: 23 mai. 2014.

3 Acerca da globalização, Denis Borges Barbosa assinala que: "Os fatores que levam à globalização do mercado conduzem, quase que necessariamente, a uma uniformidade de proteção jurídica. A racionalidade do sistema exige, pelo menos, que não haja um excesso de condições de desigualdade, induzido pela legislação de direito intelectual, que conduza uma empresa a instalar unidades fabris em um território onde naturalmente não viria a produzir, ou que afaste a empresa de um território onde naturalmente tenderia a se instalar ou vender." (BARBOSA Denis Borges. Propriedade intelectual: a aplicação do acordo TRIPS. Rio de Janeiro: Ed. Lumen

Juris, 2003, p. 7).

4 HABERMAS, Jürgen. A constelação pós-nacional. Ensaios políticos. São Paulo: Littera Mundi, 2012.

5 Nesse sentido, RONALD DWORKIN afirma que: "Se duas regras entram em conflito, uma delas não pode ser válida. A decisão de saber qual deve ser abandonada ou reformulada, deve ser tomada recorrendo-se a considerações que estão além das próprias regras. Um sistema jurídico pode regular esses conflitos através de outras regras, que dão precedência à regra promulgada pela autoridade de grau superior, á regra promulgada mais recentemente, á regra mais específica ou outra coisa desse gênero. Um sistema jurídico também pode preferir a regra que é sustentada pelos princípios mais importantes.” (DWORKIN, Ronald. Levando os direitos a sério. São Paulo: Martins Fontes, 2002). 
as regras de direito material visando a construção de um direito comum .

A professora faz referência a um "país das nuvens em ordem". As nuvens seriam o inverso do direito, passando a imagem de desordem e arbitrariedade. Assim, há necessidade de um "direito dos direitos" que aproxime, harmonicamente, os diferentes sistemas, não os unifique. Ou seja, que ordene as nuvens, guardando seu ritmo e suas formas próprias.

Delmas-Marty chama de processo evolutivo e interativo essa troca horizontal de normas (diálogo entre juízes). Por exemplo: quando a Corte Suprema dos EUA cita a Corte Europeia dos Direitos Humanos, ou vice-versa. Instaura-se, aqui, segundo a professora, uma ordem jurídica nem puramente nacional nem verdadeiramente mundial, que ela denominou "pluralismo ordenado", que nada mais é do que uma ordem não uniforme, mas pluralista que associa um direito mundial aos direitos nacionais e regionais.

A proposta da professora Delmas-Marty é de uma verdadeira inovação, ou seja, os antigos modelos têm que ser adaptados à nova e atual realidade, na tentativa de ordenar os sistemas jurídicos internos, embora sem uniformizá-los. Conquanto se possa questionar a viabilidade jurídica e as vantagens práticas dessa uniformização ${ }^{7}$, a circunstância

irreversível é de que a mundialização do direito é, na prática, possível; se ela é juridicamente racional e se ela é eticamente desejável. ${ }^{8}$

Tal fenômeno encontra um espaço interessante de estudo no campo da propriedade intelectual por duas razões: elevado grau de uniformização das normas de propriedade intelectual e o enfrentamento de problemas similares na inclusão de novas tecnologias pelo sistema de propriedade intelectual.

A definição de parâmetros mais precisos quanto à influência da jurisprudência alienígena na construção do direito internacional tal como aplicado em nosso país poderá contribuir para a

6 Sobre o direito comum, Mireille Delmas-Marty coloca a questão enfocando que: "É verdade que os sistemas jurídicos continuam inábeis para "pensar o múltiplo”. Trate-se de prescrever uma norma, de interpretá-la ou legitimá-la por referência a valores metajurídicos, nossos esquemas de pensamento permanecem muito marcados pela época das Luzes. Regras precisas, um raciocínio silogístico e valores homogêneos - em suma uma ordem "monológica" - têm de longe a preferência dos juristas.” (DELMAS-MARTY, Mireille. Por um direito comum. São Paulo: Martins Fontes, 2004, p. 202).

7 A professora Delmas-Marty faz os seguintes questionamentos: se a mundialização do direito é, na prática, possível; se ela é juridicamente racional e se ela é eticamente desejável (DELMAS-MARTY, Mireille. Três Desafios para um Direito Mundial. trad. Fauzi Hassan Choukr, São Paulo: Ed. Lumen Iures, 2003).

8 DELMAS-MARTY, Mireille. Três Desafios para um Direito Mundial. trad. Fauzi Hassan Choukr, São Paulo: Ed. Lumen Iures, 2003. 
definição de políticas públicas internas quanto à aplicação dos acordos e convenções internacionais em matéria de propriedade intelectual.

\section{CONVENÇÕES E ACORDOS INTERNACIONAIS EM MATÉRIA DE PROPRIEDADE INTELECTUAL.}

Parte-se da premissa de que a proteção à propriedade intelectual nasce exclusivamente da lei, necessitando, portanto, da intervenção estatal para a criação de leis que possam regulamentá-la. Pode ser definida como o instrumento que protege os direitos relacionados às obras literárias e artísticas, aos fonogramas, às invenções, aos desenhos industriais, aos direitos do autor, às patentes, às marcas, às indicações geográficas, às firmas e denominações comerciais, à proteção contra a concorrência desleal e a todos os demais produtos da atividade intelectual nos domínios industrial, científico, literário e artístico.

As categorias da propriedade intelectual são: a) direitos autorais, que abrangem as obras intelectuais, literárias e artísticas, além dos programas de computador e domínios na Internet; e b) propriedade industrial, que seriam as marcas, patentes, desenho industrial, indicações geográficas, proteção de cultivares e topografia de circuitos integrados.

Assim, para garantir a possibilidade de se obter proteção de marcas, patentes e direitos autorais em diferentes países, surgem algumas convenções e acordos internacionais, regulando o tema da propriedade intelectual em caráter internacional e estabelecendo princípios e garantias, sem prejuízo das legislações internas dos países signatários.

Deve-se ressaltar não apenas o tradicional entendimento segundo o qual os tratados apenas ingressam no ordenamento interno a partir da edição de leis ordinárias que os incorporem, hipótese em que assumirão status equiparado ao das leis ordinárias, mas também, uma resistência quanto à admissão de que os tratados sobre propriedade intelectual assumam a categoria de leis uniformes.

Nesse sentido, identifica-se que os tratados, de forma geral, têm estatura de lei e, uma vez incorporados em nosso ordenamento jurídico por meio da edição de lei, a competência para interpretá-los é do STJ. Necessária, portanto, sua integração por meio de normas internas. Exceção a essa regra são os tratados que versam sobre Direitos Humanos os quais ingressam no nosso ordenamento na categoria de normas supralegais, sendo possível, ainda que alçarem no mesmo status 
das emendas constitucionais, quando observado o rito do parágrafo $3^{\circ}$ do art. $5^{\circ}$ da $\mathrm{CF}$.

No cenário internacional destacam-se, quanto ao tema, os seguintes tratados: a Convenção de Berna sobre Direitos Autorais, de 1886, que estabelece normas para os direitos de propriedade intelectual; e a Convenção da União de Paris para a Proteção da Propriedade Industrial, assinado em 1883 por vários países, inclusive pelo Brasil, com a finalidade de estabelecer regras uniformes ao redor do mundo, sem retirar, contudo, a liberdade de seus signatários dentro de seus respectivos países.

O tratado da Convenção da União de Paris sofreu algumas revisões desde que foi assinado, dentre elas, Bruxelas, em 1900; Washington, em 1911, Haia, em 1925; Londres, em 1934; Lisboa, em 1958; e Estocolmo, em 1967, que é a que vigora até os dias atuais. No Brasil, tem-se o Decreto n. 75.572, de 1975, que conferiu eficácia a várias legislações de propriedade intelectual, tais como as Leis 9.279/96, sobre marcas e patentes e a proteção contra concorrência desleal; 9.456/97, sobre cultivares; 9.609/98, sobre Software; e 9.610/98, sobre direitos autorais e conexos.

Além desses tratados, tem-se o Acordo TRIPS (Trade Related Intelectual Property Rights), assinado em 1994, na Rodada Uruguai, que serviu para estabelecer critérios mínimos definidores de direitos a serem concedidos pelos Estados membros aos titulares de direitos oriundos da propriedade intelectual, visando à globalização e à transferência de tecnologia mundial.

O Acordo TRIPS, objetivando estabelecer um manual de uniformização para os Estadosmembros, criou obrigações para que fossem editadas legislações internas para adaptação aos padrões internacionais ali estabelecidos. Os efeitos do Acordo se condicionaram a um prazo para que suas regras entrassem em vigor, conforme o grau de desenvolvimento econômico dos Estados-partes.

O Brasil, na condição de país em desenvolvimento, cumprindo o determinado no TRIPS e seguindo as regras internas de aprovação dos tratados internacionais, aprovou o Decreto n. 1.355/94, c uja eficácia, tanto interna quanto internacional, está condicionada ao transcurso do prazo do período de transição previsto no art. 65.2 do TRIPS $^{9}$, período esse de extrema importância por dizer respeito à adaptação de leis referentes aos direitos da propriedade intelectual em todos os países signatários. Transcorrido o período de transição, cabe ao legislador nacional promover a adaptação das regras internas aos padrões internacionais.

9 BASSO, Maristela. A data de aplicação do TRIPS no Brasil. In Revista de Direito Constitucional e Internacional. São Paulo: RT, n. 30, Ano 8, janeiro-março de 2000, p. 13. 
Assim, o TRIPS entrou em vigor no Brasil, em $1^{\circ}$ de janeiro de $2000^{10}$, regulando a propriedade intelectual externa e internamente. Surgem alguns questionamentos, em especial por Denis Barbosa. Por exemplo: o TRIPS cria direitos e obrigações para os Estados membros, mas não para as partes privadas. Nesses termos, o Acordo determina que os Estados membros legislem livremente, respeitados certos padrões mínimos, mas não muda por si só a lei interna. Dito de outra forma, ele exige lei interna, mas não é lei interna.

A título de ilustração observe-se que o Código de Propriedade Intelectual (Lei 9.279/96) aumentou o prazo das patentes a partir de 1997 (sem esperar o ano de 2000), o Brasil dispensou o resto do benefício especial dos países em desenvolvimento. Entretanto, a nova lei interna não mandou estender o prazo das patentes já concedidas. Fica claro, assim, que o Acordo TRIPS, por si só, não prorroga patentes.

Ainda no cenário internacional, merecem destaque as organizações internacionais OMC (Organização Mundial do Comércio) e OMPI (Organização Mundial da Propriedade Intelectual). No Brasil, o Instituto Nacional da Propriedade Industrial (INPI) é o órgão responsável pelo registro e proteção das marcas, patentes, desenho industrial, transferência de tecnologia, indicação geográfica, programa de computador e topografia de circuito integrado.

\section{JULGADOS DO SUPERIOR TRIBUNAL DE JUSTIÇA}

O questionamento que se faz é de como se dá a internacionalização do direito pela jurisprudência do Superior Tribunal de Justiça em processos de propriedade intelectual. Não se trata aqui da eficácia das decisões estrangeiras em território nacional, uma vez que, para isso, existe a homologação de setença estrangeira. Tampouco se cuida da eficácia das sentenças nacionais nos demais países.

10 BRASIL. Superior Tribunal de Justiça. REsp 642.213/RJ, Segunda Seção. Rel. Ministro João Otávio de Noronha, Brasília, julgado em 28/04/2010, DJe 02/08/2010. Disponível em https://ww2.stj.jus.br/revistaeletronica/ita.asp?registro=200400038267\&dt_publicacao=02/08/2010.

(...) 5. Não há suporte legal nem obrigação do Brasil de garantir às patentes de invenção depositadas em data anterior a $1^{\text {o }}$ de janeiro de 2000 a prorrogação por 5 (cinco) anos do prazo de validade - originalmente estabelecidos em 15 (quinze) anos -, de forma a vigorar por 20 (vinte) anos a proteção patentária em território nacional, mediante a aplicabilidade direta e sem reservas do Acordo TRIPs.

Rev. de Direito, Inov, Propriedade Intelectual e Concorrência | e-ISSN: 2526-0014 | Minas Gerais | v. 1 | n. 2 | p. 143 - 158 | Jul/Dez. 2015. 
Objetiva-se examinar a consideração dispensada pelo Superior Tribunal de Justiça à fundamentação lançada em sentenças estrangeiras que tratem de propriedade intelectual para efeito de uniformidade da aplicação de normas internacionais sobre o tema. Busca-se investigar como o Superior Tribunal de Justiça, a partir dos avanços da ciência e do fenômeno da globalização, recepciona os tratados e acordos internacionais, em matéria de propriedade intelectual.

O papel que essa Corte Superior de Justiça exerce na construção de uma comunidade mundial de juízes, preocupados com a aplicação uniforme das regras de direito material em questão e com a construção de um direito comum quanto ao tema, pode ser revelado a partir da análise dos seus próprios julgados. Examinando-se esses mesmos julgados observa-se, no entanto, que, em questões controversas dirimidas pelo Superior Tribunal de Justiça no tocante à proteção de marcas, patentes e direitos autorais, não tem sido utilizada, de forma adequada, a experiência construída em outras jurisdições com amparo na interpretação das mesmas regras de direito internacional aplicáveis internamente, ignorando- se, assim, a realidade mundial globalizada.

Os principais julgados do STJ quanto às questões suscitadas a partir da necessária interpretação/aplicação das normas de direito internacional que tratam de propriedade intelectual não se socorrem, em nenhum momento da experiência acumulada pelos órgãos jurisdicionais dos demais países signatários dessas mesmas normas.

No julgamento do Recurso Especial 960.728/RJ, publicado no Diário de Justiça eletrônico em 15.04.2009, sob a Relatoria da Ministra Nancy Andrighi, a Terceira Turma do STJ entendeu que a validade da patente de determinado produto, postergada de 15 a 20 anos, pelo acordo TRIPS, não é admitida para os casos de patente concedida sob a égide da Lei 5.772/71, mesmo porque referido acordo entrou em vigor em $1^{\circ} .1 .2000$. Assim, o prazo padrão de vinte anos para as patentes, previsto no Acordo TRIPS, não se aplica automaticamente, em nenhuma hipótese. Somente uma lei interna do Estado membro poderia prorrogar tal prazo, e, no Brasil, não existia tal lei. ${ }^{11}$

No mesmo julgamento, entendeu-se que o TRIPS não é lei uniforme, ou seja, não é um tratado que foi editado de forma a propiciar sua literal aplicação nas relações jurídicas de direito

\footnotetext{
${ }^{11}$ BRASIL. Superior Tribunal de Justiça. REsp 960.728/RJ, Terceira Turma. Relatora Ministra Nancy Andrighi, Brasília, julgado em 17/03/2009, DJe 15/4/2009. Disponível em: http://intranet/processo/pesquisa/?tipoPesquisa=tipoPesquisaNumeroRegistro\&termo=200701343888\&totalRegi strosPorPagina $=40 \&$ aplicacao $=$ processos.
} 
privado ocorrente em todos os países que a ele aderem, substituindo de forma plena a atividade legislativa desses países, que estaria então limitada à declaração de sua recepção.

Outro julgado a ser citado é o Recurso Especial 1.149.403/RJ, publicado no Diário de Justiça eletrônico em 29.11.2013, também da Relatoria da Ministra Nancy Andrighi, em que a Terceira Turma do Superior Tribunal de Justiça entendeu ser inaplicável o disposto no art. $6^{\circ}$, bis, 3, da Convenção da União de Paris ao caso em concreto, mantendo o acórdão do Tribunal de origem do Rio de Janeiro que reconheceu a prescrição, ao argumento de que, mesmo se admitindo uma interpretação extensiva do referido dispositivo legal, para admitir sua aplicação às hipóteses em que a má-fé do terceiro está no desuso da marca e não no seu uso, não prevalece a tese da imprescritibilidade

Comercial. Recurso especial. Mandado de segurança. Patentes. Pedido de prorrogação, por mais cinco anos, de patente concedida na vigência da Lei n ${ }^{\circ}$ 5.772/71, em face da adesão do Brasil ao Acordo TRIPS. Natureza do Acordo. Exame das cláusulas relativas às possíveis prorrogações de prazo de vigência do TRIPS para os países em desenvolvimento e das discussões legislativas no Congresso brasileiro durante a adesão ao Acordo.

- Quando o STJ acatou, em precedentes anteriores, a prorrogação do prazo de 15 anos previsto na anterior Lei n 5.771/71 para 20 anos, com base no acordo TRIPS, tomou por premissa necessária um fundamento que não chegou a ser questionado e que está longe de ser pacífico, segundo o qual tal Acordo, no momento de sua recepção pelo Estado brasileiro, passou a produzir efeitos sobre as relações jurídicas privadas que tinham em um dos pólos detentores de patentes ainda em curso de fruição.

- Em reexame da questão, verifica-se, porém, que o TRIPS não é uma Lei Uniforme; em outras palavras, não é um tratado que foi editado de forma a propiciar sua literal aplicação nas relações jurídicas de direito privado ocorrentes em cada um dos Estados que a ele aderem, substituindo de forma plena a atividade legislativa desses países, que estaria então limitada à declaração de sua recepção.

- O argumento de que o Brasil não demonstrou interesse em fazer valer o prazo extra de quatro anos, como

Nação em desenvolvimento, para aplicação do TRIPS desconsidera a existência de dois prazos de carência no corpo do Acordo, pois é nítida a diferença entre as redações dos $\S \S 2^{\circ}$ e $4^{\circ}$ do art. 65 . Com efeito, o $\S 2^{\circ}$, quando cria o prazo geral de aplicação de cinco anos (na modalidade $1+4$ ) fala expressamente que tal prazo é um direito do Estado em desenvolvimento; porém, ao tratar do segundo prazo adicional, no $\S 4^{\circ}$, a redação muda substancialmente, estando ali consignado que um Estado nas condições do Brasil "poderá adiar" a aplicação do Acordo em alguns pontos por mais 5 anos. A segunda ressalva é uma mera possibilidade, ao contrário da primeira.

- O Brasil, conforme demonstram as transcrições das discussões legislativas juntadas aos autos, abriu mão do segundo prazo especial e facultativo de mais cinco anos constante no art. 65.4, prazo esse destinado à extensão da proteção a setores tecnológicos ainda não protegidos pelas antigas Leis de Patentes; mas não do primeiro prazo, porque, em relação a este e pelos próprios termos do Acordo, qualquer manifestação de vontade era irrelevante.

- Em resumo, não se pode, realmente, pretender a aplicação do prazo previsto no art. 65.4 do TRIPS, por falta de manifestação legislativa adequada nesse sentido; porém, o afastamento deste prazo especial não fulmina, de forma alguma, o prazo genérico do art. 65.2, que é um direito concedido ao Brasil e que, nesta qualidade, não pode sofrer efeitos de uma pretensa manifestação de vontade por omissão, quando nenhum dispositivo obrigava o país a manifestar interesse neste ponto como condição da eficácia de seu direito. Recurso especial não conhecido.

Rev. de Direito, Inov, Propriedade Intelectual e Concorrência | e-ISSN: 2526-0014 | Minas Gerais | v. 1 | n. 2 | p. 143 - 158 | Jul/Dez. 2015. 
do requerimento para anulação do registro. ${ }^{12}$

Mais recentemente, a Quarta Turma do STJ, ao julgar ação de indenização por perdas e danos ajuizada por determinada atriz famosa contra editora de revista brasileira que tivera publicado suas fotos, argumentando-se o descumprimento de cláusulas constantes no contrato de licença de uso de imagem relativo ao ensaio fotográfico, manteve o acórdão proferido pelo tribunal de origem (Tribunal de Justiça do Estado de São Paulo), utilizando como fundamento, dentre outros dispositivos legais, o art. $2^{\circ}$ da Convenção de Berna de forma conjunta com o art. $7^{\circ}$, VII, da Lei n. 9.610/1998.

Naquele recurso especial, segundo o relator, o Ministro Luis Felipe Salomão, o ordenamento jurídico brasileiro, confere à fotografia proteção própria de direito autoral, de forma ampla e genérica. Nos termos do voto do relator, "nesse sentido, o art. 2 da Convenção de Berna, de 1886, afirma de forma genérica que "os termos 'obras literárias e artísticas'

12 BRASIL. Superior Tribunal de Justiça. REsp 1.149.403/RJ, Terceira Turma. Relatora Ministra Nancy Andrighi, Brasília, julgado em 13/08/2013, DJe 29/11/2013. Disponível em: http://intranet/processo/pesquisa/?tipoPesquisa=tipoPesquisaNumeroRegistro\&termo=200901360217\&totalRegi strosPorPagina $=40 \&$ aplicacao $=$ processos.

PROPRIEDADE INDUSTRIAL. MARCA. RECURSO ESPECIAL. CADUCIDADE. CANCELAMENTO REGISTRO. INPI. DECLARAÇÃO DE NULIDADE. PRESCRIÇÃO.

1. A marca constitui um sinal distintivo de percepção visual que individualiza produtos e/ou serviços. O seu registro confere ao titular o direito de usar, com certa exclusividade, uma expressão ou símbolo e a sua proteção, para além de garantir direitos individuais, salvaguarda interesses sociais, na medida em que auxilia na melhor aferição da origem do produto e/ou serviço, minimizando erros, dúvidas e confusões entre usuários.

2. A Convenção da União de Paris para Proteção da Propriedade Industrial confere, no seu art. $6^{\circ}$, bis, proteção

internacional às marcas notoriamente conhecidas, impedindo o registro ou determinando sua anulação, nos países integrantes da União, de marcas que constituam reprodução, imitação ou tradução suscetível de estabelecer confusão com aquela notória. O prazo para requerer o cancelamento do registro é de 5 (cinco) anos (art. $6^{\circ}$, bis, 2), salvo a hipótese de má-fé, em que, o requerimento de cancelamento do registro ou de proibição do uso poderá ser feito a qualquer tempo pelo interessado (art. $6^{\circ}$, bis, 3).

3. Na hipótese, a recorrente insurge-se contra o ato administrativo do INPI que declarou o cancelamento do registro de marca "DIXIE \& DESENHO” por motivo de desuso (caducidade). Não se pretende o cancelamento ou a proibição de uso de marca notória registrada ou utilizada de má-fé por aquele que não seja o seu titular.

4. A Convenção da União de Paris, no seu art. $6^{\circ}$, bis, não trata da hipótese de anulação do ato que cancelou o registro da marca por desuso (caducidade).

5. Ainda que se aceite uma interpretação extensiva do dispositivo (art. $6^{\circ}$, bis, 3), para admitir sua aplicação às hipóteses em que a má-fé do terceiro está no desuso da marca e não no seu uso, a tese da imprescritibilidade do requerimento para anulação do registro não convence. Ela não é a regra no direito brasileiro, sendo admitida somente em hipóteses excepcionalíssimas que envolvem direitos da personalidade, estado das pessoas, bens públicos. Os direitos patrimoniais, por sua vez, estão sujeitos aos prazos prescricionais do Código Civil ou das leis especiais.

6. Deve se reconhecer a inaplicabilidade do disposto no art. $6^{\circ}$, bis, 3, da Convenção da União de Paris à hipótese.

7. Recurso especial desprovido. 
abrangem [...] as obras fotográficas e as expressas por um processo análogo ao da fotografia".", 13

Nota-se pelo que foi exposto que, nesse processo de cooperação jurídica internacional, os julgados do Superior Tribunal de Justiça denotam certo distanciamento do fenômeno da internacionalização do Direito, no que diz respeito à uniformização da jurisprudência nacional na interpretação das normas internacionais de propriedade intelectual, cujo regramento advenha de tratados e acordos internacionais. ${ }^{14}$ Ressalte-se que, nessa pesquisa, foram analisados os acórdãos relacionados à Convenção de Berna, à Convenção da União de Paris, e também ao acordo TRIPS.

${ }^{13}$ BRASIL. Superior Tribunal de Justiça. REsp 1.3221704/SP, Quarta Turma. Relator Ministro Luis Felipe Salomão, Brasília, julgado em 23/10/2014, DJe 19/12/2014. Disponível em: https://ww2.stj.jus.br/processo/revista/inteiroteor/?num_registro=201200920344\&dt_publicacao=19/12/2014

DIREITO CIVIL. DIREITO DE IMAGEM VS DIREITO AUTORAL. ENSAIO FOTOGRÁFICO. VIOLAÇÃO A ARTIGO DA LEI DE DIREITOS AUTORAIS. DESCABIMENTO. DIREITOS DA PERSONALIDADE. EXPLORAÇÃO. CESSÃO. DIREITO DE IMAGEM. ALCANCE CONTRATUAL. INCIDÊNCIA DA SÚMULA N. 5/STJ.

1. O ordenamento jurídico brasileiro, de forma ampla e genérica, confere à fotografia proteção própria de direito autoral. Art. $7^{\circ}$, inciso VII, da Lei n. 9.610/1998 e art. 2 da Convenção de Berna.

2. Porém, em se tratando de fotografia, para efeitos de proteção do direito autoral das obras artísticas, é autor o fotógrafo e não o fotografado, este último titular de outros direitos da personalidade, como a imagem, a honra e a intimidade. É o fotógrafo o detentor da técnica e da inspiração, quem coordena os demais elementos complementares ao retrato do objeto - como iluminação -, é quem capta a oportunidade do momento e o transforma em criação intelectual, digna, portanto, de tutela como manifestação de cunho artístico.

3. A modelo fotografada não goza de proteção do direito autoral, porque nada cria, dela não emana nenhuma criação do espírito exteriorizada como obra artística. Sua imagem compõe obra artística de terceiros. Portanto, descabe analisar a apontada ofensa ao art.

$4^{\circ}$ da Lei de Direitos Autorais, uma vez que tal dispositivo não socorre à modelo fotografada, a qual não é titular de direitos autorais oponíveis contra a editora da revista na qual as fotos foram divulgadas.

4. Dissídio jurisprudencial não demonstrado. Casos confrontados que não guardam similitude fática nem merecem soluções jurídicas idênticas. A ideia de que a cessão de direitos de imagem não deve ser interpretada ampliativamente está, a rigor, correta (Arts. 11 e 20 do Código Civil de 2002). Isso, todavia, não afasta métodos também consagrados de hermenêutica contratual que incidiriam no caso em apreço, como aquele segundo o qual "nas declarações de vontade se atenderá mais à sua intenção que ao sentido literal da linguagem" (art. 85 do CC/1916 e art. 112 do CC/2002); o de que os negócios jurídicos devem ser interpretados conforme os usos e costumes (art.113, CC/2002); ou que "o silêncio importa anuência, quando as circunstâncias ou os usos o autorizarem, e não for necessária a declaração de vontade expressa" (art. 111 do CC/2002).

Rev. de Direito, Inov, Propriedade Intelectual e Concorrência | e-ISSN: 2526-0014 | Minas Gerais | v. 1 | n. 2 | p. 143 - 158 | Jul/Dez. 2015. 
5. Com efeito, a solução buscada pela recorrente encontra óbice intransponível na Súmula 5/STJ, pois demandaria reexame de cláusulas contratuais, cláusulas essas cujo alcance - sobretudo em um cenário de dúvida, como amiúde ocorre - não se limita à mera releitura de sua literalidade incontroversa.

6. Recurso especial parcialmente conhecido e não provido. (REsp 1322704/SP, Rel. Ministro LUIS FELIPE SALOMÃO, QUARTA TURMA, julgado em 23/10/2014, DJe 19/12/2014) 14 DA SILVA, Ricardo Perlingeiro Mendes. Reconhecimento de decisão judicial estrangeira no Brasil e o controle da ordem pública internacional no regulamento (CE) 44: análise comparativa. In Revista de Processo, Ano 29, novembro-dezembro de 2004, p. 173.

\section{CONCLUSÃO}

Da análise feita acerca do presente trabalho, apresentam-se as seguintes

1) O fenômeno denominado "diálogo entre juízes" tem sido defendido por alguns doutrinadores, como forma de reduzir as incoerências do sistema jurídico alienígena frente à crescente fragmentação do direito internacional. No direito constitucional, destaca-se Marcelo Neves, enquanto nos Direitos Humanos, a frente doutrinária é ocupada por Mireille Delmas-Marty e Laurence Bougorgue-Larsesn.

2) No Direito de Propriedade Intelectual ainda não há trabalhos que explore o diálogo entre juízes de diferentes ordenamentos. Porém, esse fenômeno tem se revelado, nos sistemas que o adotam, um instrumento valioso para construção de princípios e argumentos capazes de informar uma prestação jurisdicional consentânea com a envergadura dos conflitos de direitos fundamentais hoje verificados.

3) Há, pelo menos, duas razões que dão espaço interessante de estudo no campo da propriedade intelectual, quais sejam: elevado grau de uniformização das normas de propriedade intelectual e o enfrentamento de problemas similares na inclusão de novas tecnologias pelo sistema de propriedade intelectual.

4) A definição de parâmetros mais precisos quanto à influência da jurisprudência alienígena na construção do direito internacional tal como aplicado em nosso país poderá contribuir para a definição de políticas públicas internas quanto à aplicação dos acordos e convenções internacionais em matéria de propriedade intelectual.

5) Para garantir a possibilidade de se obter proteção de marcas, patentes e direitos autorais em diferentes países, surgem algumas convenções e acordos internacionais, regulando o tema da propriedade intelectual em caráter internacional e estabelecendo princípios e garantias, sem 
prejuízo das legislações internas dos países signatários. Neste Trabalho são destacadas a Convenção de Berna sobre Direitos Autorais; a Convenção da União de Paris para a Proteção da Propriedade Industrial e o Acordo TRIPS.

6) Ao se examinar a consideração dispensada pelo Superior Tribunal de Justiça à fundamentação lançada em sentenças estrangeiras que tratem de propriedade intelectual para efeito de uniformidade da aplicação de normas internacionais sobre o tema, chega-se à conclusão que o impacto que os tratados e acordos internacionais causam no direito de propriedade intelectual perante o Superior Tribunal de Justiça, atualmente, não são significativos para a cooperação ao diálogo entre juízes.

7) A jurisprudência do Superior Tribunal de Justiça recusa a aplicabilidade imediata das convenções e acordos internacionais, fazendo-se necessária sua integração por meio de normas internas. Há, assim, uma resistência quanto à admissão de tratados sobre propriedade intelectual à categoria de leis uniformes. 


\section{REFERÊNCIAS}

BARBOSA, Denis Borges. Propriedade intelectual: a aplicação do acordo TRIPS. Rio de Janeiro: Ed. Lumen Juris, 2003.

BASSO, Maristela. A data de aplicação do TRIPS no Brasil. In Revista de Direito Constitucional e Internacional. São Paulo: RT, n. 30, Ano 8, janeiro-março de 2000, p. 13.

BECK, Ulrick. O que é globalização? Equívocos do Globalismo: respostas à globalização. São Paulo: Paz e Terra, 1999.

BRASIL. Superior Tribunal de Justiça. REsp 642.213/RJ, Segunda Seção, Rel. Ministro João Otávio de Noronha, Brasília, julgado em 28/04/2010, DJe 02/08/2010. Disponível em: https://ww2.stj.jus.br/revistaeletronica/ita.asp?registro=200400038267\&dt_publicacao=02/08/ 2010.

BRASIL. Superior Tribunal de Justiça. REsp 960.728/RJ, Terceira Turma, Relatora Ministra Nancy Andrighi, Brasília, julgado em 17/03/2009, DJe 15/4/2009. Disponível em: http://intranet/processo/pesquisa/?tipoPesquisa=tipoPesquisaNumeroRegistro \&termo=200701 343888\&totalRegistrosPorPagina=40\&aplic acao=processos.

BRASIL. Superior Tribunal de Justiça. REsp 1.149.403/RJ, Terceira Turma, Relatora Ministra Nancy Andrighi, Brasília, julgado em 13/08/2013, DJe 29/11/2013. Disponível em: http://intranet/processo/pesquisa/?tipoPesquisa=tipoPesquisaNumeroRegistro \&termo=200901 360217\&totalRegistrosPorPagina=40\&aplicacao=processos.

BRASIL. Superior Tribunal de Justiça. REsp 1.3221704/SP, Quarta Turma. Relator Ministro Luis Felipe Salomão, Brasília, julgado em 23/10/2014, DJe 19/12/2014. Disponível em: https://ww2.stj.jus.br/processo/revista/inteiroteor/?num_registro=201200920344\&dt_publicac ao $=19 / 12 / 2014$ 
DA SILVA, Ricardo Perlingeiro Mendes. Reconhecimento de decisão judicial estrangeira no Brasil e o controle da ordem pública internacional no regulamento (CE) 44: análise comparativa. In Revista de Processo, Ano 29, novembro-dezembro de 2004, p. 173.

DELMAS-MARTY, Mireille. Por um direito comum. São Paulo: Martins Fontes, 2004. DELMAS-MARTY, Mireille. Três Desafios para um Direito Mundial. trad. Fauzi Hassan Choukr, São Paulo: Ed. Lumen Iures, 2003.

DWORKIN, Ronald. Levando os direitos a sério. São Paulo: Martins Fontes, 2002. HABERMAS, Jurgen. A constelação pós-nacional. Ensaios políticos. São Paulo: Littera Mundi, 2012.

LARSEN-BURGORGUE, Laurence. A internacionalização do diálogo dos juízes: missiva ao Sr. Bruno Genevois, presidente do Conselho de Estado da França. Revista Prismas, v. 7, n. 1, p. 261-304, jan./jun. 2010. Disponível em: <http://www.publicacoesacademicas.uniceub.br/ index.php/prisma/article/view/1145/989>. Acesso em: 29 abr. 2012.

LOPES, Carla Patrícia F. Nogueira. Internacionalização do direito e pluralismo jurídico: limites de cooperação no diálogo entre juízes. Revista de Direito Internacional, Brasília, v. 9, $\mathrm{n}$. 4, 2012, p. 229-247. Disponível em: <http://www.tjdft.jus.br/institucional/imprensa/noticias/arquivos/Carla.pdf>. Acesso em: 23mai. 2014.

NEVES, Marcelo. Transconstitucionalismo. São Paulo: Martins Fontes, 2009. 